\title{
Injury research and violence: what's our contribution?
}

As I write this piece, the US Congress is considering a bill to prevent the National Center for Injury Prevention and Control (NCIPC) of the Centers for Disease Control and Prevention from funding any research on injuries related to firearms. ${ }^{1}$ This is being pursued at the request of the National Rifle Association (NRA) and some conservative congressmen. These individuals claim that much of the past firearm research has been duplicative of other work, has not been scientific, and has been conducted with a bias towards gun control..$^{23}$ These individuals believe that such research should be pursued by the National Institute of Justice and by criminologists, not by medical or public health types.

What is our role in research to prevent intentional injuries to children and adolescents? Should we be involved, or should we leave this solely to the criminal justice system? Are the NRA and some professionals in the criminal justice community ${ }^{4}$ right when they say we should stick with studying 'accidents'? I believe we should and must be involved in research on intentional injuries for a number of reasons:

Intentional injuries ARE a health problem. As individuals concerned with reducing morbidity and mortality from injuries to children and adolescents, and as child advocates, we must address intentional injuries as well as unintentional ones. Injuries from child abuse are seen around the world; assaults in older children and adolescents may be more deadly in the US because of easy access to guns, but they are common everywhere. ${ }^{5}$ Adolescent suicide is an issue for both industrialized and non-industrialized countries. ${ }^{6}$ This concern with the health consequences of violence is what makes us distinct from the criminal justice community. It would be irresponsible for us to ignore these injuries and the means by which they occur.

The tools to study injuries are the same, regardless of whether they are intentional or unintentional. The science of modern epidemiology has proven to be a powerful tool for unraveling the web of causation and understanding the etiology of disease processes. Understanding who is at risk of injury, under what circumstances, in what environments, and using what products, has directed interventions and has allowed us to evaluate their success. Understanding the risk of swimming pools led to the introduction of pool fencing as an effective countermeasure. $^{7}$ Demonstrating the effectiveness of bicycle helmets led to successful programs to increase their use and decrease head injuries from cycling. ${ }^{8}$ The same has been and can be true of intentional injuries. Understanding the risks of suicide associated with coal gas in the home led to its elimination and subsequent reduction in deaths from suicide in the UK. ${ }^{9}$ Realizing that pesticides sold openly in stores were the most common means of teen suicide opened the way for programs to reduce adolescent suicide in Sri Lanka. ${ }^{10}$

The medical and public health community $H A V E$ raised the level of consciousness about intentional injury. Dr C Henry Kempe was the first to describe the injuries to children resulting from abuse, the 'battered child syndrome'." Efforts by the NCIPC in the US have been successful in drawing public attention to the large increase in youth violence over the last 15 years in the US. The Surgeon General's stand on domestic violence ${ }^{12}$ has brought this to the forefront of public attention, leading to better identification of victims as well as more appropriate responses by the police and criminal justice.

The basic methods for prevention of intentional injuries are the same as those for unintentional injuries. The tools of education, environmental/product modification, and legislation/enforcement are applicable to all injuries, whether they be intentional or unintentional, albeit the relative effectiveness may vary tremendously from one injury problem to another. Education combined with legislation has been successful in most countries in increasing seat belt and car seat usage rates. In contrast, education may do little to decrease gun injuries from assault, whereas legislation with appropriate enforcement can have substantial effects.

We need to be inclusive in our approach to child and adolescent injury control and examine both intentional and unintentional injuries. Appropriate caution should be used when dealing with the problem of intentional injuries, however. We should neither ignore nor deny the substantial contributions made to this area by the criminal justice community, sociologists, or criminologists. We should also not take complete ownership of a problem that has its underlying roots in the social, economic, and cultural fabric of a community and nation. We should continue to focus on the issue in which we have expertise: research into the etiology and prevention of injuries to children and adolescents, regardless of whether these injuries are intentional or not. To forbid the scientific community to do research on one of the most important causes of morbidity and mortality is equivalent to the burning of books. Lack of knowledge is a devil that can only hurt us all.

FREDERICK P RIVARA Chair, ISCAIP

Harborview Injury Prevention and Research Center, Box 359960, 325 Ninth Ave,

Seattle, WA 91804, USA

(Phone + 1206 521 1530, fax +1 206521 1562, e-mail fpr@u.washington.edu)

1 Montgomery L. House will vote on future of federal firearms research Seattle Times 11 July 1996: A7.

2 Blackman PH. Firearm violence and public health. $\mathcal{F} A M A 1994 ; 272$ 1406-7.

3 Blackman P. Gun laws [letter; comment]. Lancet 1993; 342: 111-2.

4 Kleck G. Guns in the medical literature [letter; comment]. 7 Med Assoc Ga 1994; 83: 324-6.

5 Rushton JP. Race and crime: international data for 1989-1990. Psychol Rep 1995; 76: 307-12.

6 Diekstra R, Garnefski N. On the nature, magnitude, and causality of suicida behaviors: an international perspective. Suicide Life Threat Behav 1995; 25: $36-57$.

7 Nixon J, Pearn J, Wilkey I, Corcoran A. Fifteen years of child drowning - a 1967-1981 analysis of all fatal cases from the Brisbane drowning study 1986; 18: 199-203.

Rivara FP, Thompson DC, Thomson RS, et al. The Seattle children's bicycle helmet campaign: changes in helmet use and head injury admisbicycle helmet campaign: changes

9 Kreitman N. The coal gas story: United Kingdom suicide rates, 1960-1971. Br F Prev Soc Med 1976; 30: 86-93.

10 Berger LR. Suicides and pesticides in Sri Lanka. Am f Public Health 1988 78: 826-8.

11 Kempe $\mathrm{CH}$, Silverman FN, Steele BF, et al. The battered child syndrome. FAMA 1962; 181: 17-24.

12 Novello AC. A medical response to domestic violence. $\mathcal{F} A M A$ 1992; 667: 3132 . 